\title{
Endoscopic biliary stenting in a district general hospital
}

\author{
K J M Rao, N M Varghese, H Blake, A Theodossi
}

\begin{abstract}
During a 48 month period to December 1990, 367 patients, median age 75 years, with obstructive jaundice caused by common bile duct stones (201), malignant biliary obstruction (148), and benign biliary strictures (18), underwent therapeutic endoscopic retrograde cholangiopancreatography. Endoscopic biliary stenting and drainage was achieved in 343 of 367 patients attempted $(93 \%)$, seven patients requiring a combined percutaneous endoscopic approach. Endoscopic stenting failed in 24 patients because of malignant duodenal infiltration (10), Billroth 2 gastrectomy (6), tight and extensive biliary strictures (6), peripapillary diverticulum (1), and technical failure (1). Prolonged follow up was available in $91 \%$ (311 of 343). The 30 day mortality was $5 \%$ (17 of 343$)$, which included two procedure related deaths $(0.6 \%)$ from fulminant pancreatitis and major sphincterotomy site bleeding. Early complications occurred in 14\% (48 of 343) and late complications occurred in $11.9 \%$ (35 of 294) patients, as of the original 343, 17 had died within 30 days and another 32 were lost to follow up. Eighty patients with incomplete bile duct clearance and eight patients with benign biliary strictures had biliary stents inserted for 12-48 months (median 30). Endoscopic biliary stenting services are necessary in a district general hospital with technical success, death and morbidity rates comparable to other studies.

(Gut 1995; 37: 279-283)
\end{abstract}

Keywords: endoscopy, biliary stenting.

Endoscopic endoprosthesis insertion has a well established place in the treatment of biliary obstruction and has been undertaken with considerable success at specialist referral centres. ${ }^{1-5}$ The need, feasability, and safety of endoscopic biliary stenting in a district general hospital, requires further assessment.

In malignant biliary obstruction endoscopic biliary stenting provides palliation by relieving

TABLE I Indications for biliary stenting

and Radiology, Mayday University Hospital, Thornton Heath, Surrey

H Blake

Correspondence to: Dr A Theodossi, Mayday University Hospital, Thornton Heath, Surrey CR7 7YE

Accepted for publication 7 December 1994

\begin{tabular}{llll}
\hline & $\begin{array}{l}\text { Common bile } \\
\text { duct stones } \\
(n)\end{array}$ & $\begin{array}{l}\text { Benign } \\
\text { strictures } \\
(n)\end{array}$ & $\begin{array}{l}\text { Malignant } \\
\text { obstruction } \\
(n)\end{array}$ \\
\hline Attempted & 201 & 18 & 148 \\
Successful & $195^{\star}$ & 18 & $130^{\star}$ \\
\hline
\end{tabular}
patients with malignant obstruction and two patients with common bile duct stones.
^Combined percutaneous endoscopic approach needed in five cholestasis and the symptoms of pruritus and nausea. ${ }^{126}$ In biliary obstruction caused by common bile duct stones, endoscopic stenting has a role when bile duct clearance is incomplete and the patient is at high risk for surgical treatment. ${ }^{78}$ Although there are few longterm studies, ${ }^{7910}$ the practice of biliary stenting in patients with retained bile duct stones, is becoming more widespread and in selected cases, may offer an effective alternative approach of biliary drainage. ${ }^{7-13}$

We report our experience of endoscopic biliary stenting, in 343 successfully stented patients at the Mayday University Hospital, which is an 800 bed district general hospital, over a period of four years and also assess the safety and efficacy of longterm stenting in patients with retained common bile duct stones.

\section{Methods}

\section{Patients}

Between January 1987 to December 1990, endoscopic endoprosthesis insertion was attempted in 367 patients with a clinical and radiological diagnosis of biliary obstruction. Two hundred and seventy five patients were from the Croydon area (population: 300 000) and 92 patients, were referred from other hospitals in the South West Thames Region. There were 212 women and 155 men, having a median age of 75 years (range 21-95). The indications for endoscopic biliary stenting were, malignant biliary obstruction (148), common bile duct stones (201), and benign biliary strictures $^{14}$ (Table I).

\section{Study design}

Patients were admitted one day before the procedure. After obtaining informed consent, the haemoglobin, platelet count, and prothrombin time were estimated and two units of blood cross matched. Prophylactic antibiotics were given one hour before and for 48 hours after the procedure. Endoscopic retrograde cholangiopancreatography (ERCP) and sphincterotomy were undertaken as previously described, ${ }^{1516}$ using an Olympus OES TJF 20 duodenoscope.

In patients with common bile duct stones, attempts at stone extraction were made using balloon catheters, baskets, and mechanical lithotripsy devices. ${ }^{14}$ If duct clearance was not achieved, an $8 \mathrm{~F}$ pigtail endoprosthesis was inserted over an $0.35 \mathrm{~mm}$ guidewire, using an $8 \mathrm{~F}$ pusher. In patients who had a stricture confirmed at cholangiography, an $0.35 \mathrm{~mm}$ guidewire was introduced across the stricture, ${ }^{5}$ 


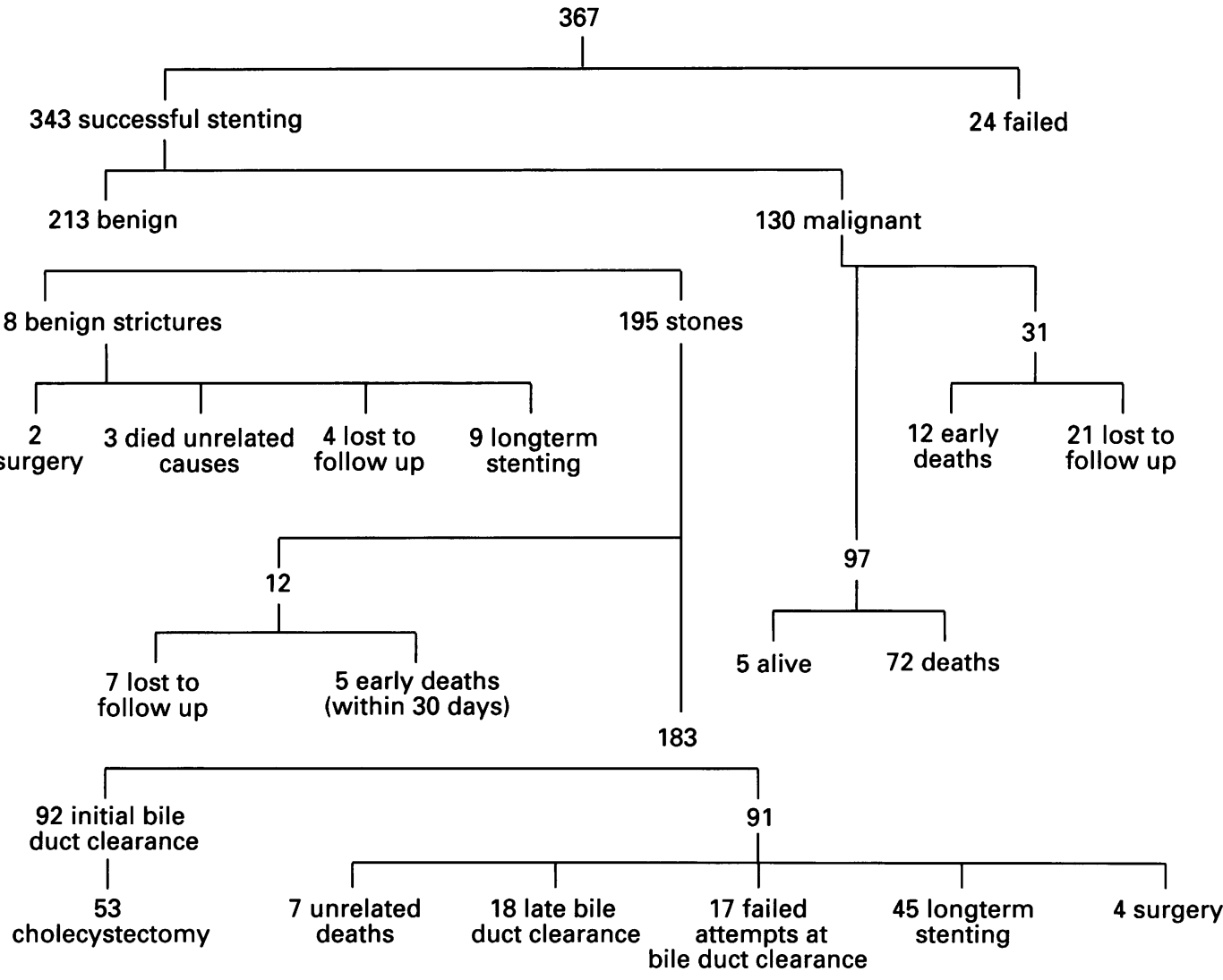

Outcome of 367 jaundiced patients with biliary obstruction.

a $6 \mathrm{~F}$ guiding catheter was inserted over the guidewire, and the stricture dilated using a 10 or $12 \mathrm{~F}$ dilator or Olbert balloon. ${ }^{17}$ Finally a 10 or $12 \mathrm{~F}$ endoprosthesis was inserted over the guiding catheter, using a $10 \mathrm{~F}$ pusher. A combined percutaneous endoscopic approach ${ }^{18}$ was required in five patients with malignant biliary obstruction and in two patients with impacted ampullary stones.

Complications occurring within the first 30 days of the procedure, were described as early and those thereafter, as late complications. Bleeding from the spincterotomy site treated with local adrenaline injection (1 in 10000 up to $14 \mathrm{ml}$ ) and not associated with haematemesis, melaena or fall in the haemoglobin of more than one gram was considered minor. Continued bleeding not controlled by adrenaline and associated with haematemesis, melaena or a fall in haemoglobin of more than one gram requiring blood transfusion was considered major bleeding. Cholangitis was defined as fever of $38^{\circ} \mathrm{C}$ or more, after excluding other causes of fever although in none of these cases was an organism grown in blood cultures. Retroperitoneal perforation was diagnosed if a contrast leak was seen during the ERCP although free air on radiography was not seen in all the cases. Pancreatitis was diagnosed clinically and biochemically (amylase greater than three times normal). To anticipate late complications, endoscopic reviews/stent replacement was arranged every four to six months in patients with malignant disease and every 12 months in those with benign biliary disease.

The final diagnosis was established in all patients by prolonged clinical follow up, imaging, and biopsy techniques and where appropriate laparatomy or necropsy findings. Results were analysed up to December 1990 and follow up was obtained, by reviewing the patients and by contacting both general practitioners and relatives of the patients.

\section{Results}

The Figure is a tree diagram showing the outcome of all 367 patients. For a more detailed description of these patients, they are considered separately under the headings of malignant biliary obstruction, common bile duct stones, and benign biliary strictures

\section{Malignant biliary obstruction}

Endoscopic biliary stenting drainage was established in 130 of 148 patients attempted $(85 \%)$, but failed in 18 patients because of malignant duodenal infiltration (10), extensive or tight biliary strictures (6), and previous Billroth 2 gastrectomy (2). Five patients needed a combined percutaneous endoscopic approach. Biliary obstruction resulted from carcinoma pancreas (68), cholangiocarcinoma (30), ampullary carcinoma (15), metastatic deposits (13), and gall bladder carcinoma (4). The median bilirubin was $200 \mu \mathrm{mol} / \mathrm{l}$ (normal range $0-17$ ).

Early complications occurred in 17 of 130 patients $(13 \cdot 1 \%)$. Only three of six patients who bled after sphincterotomy needed a blood transfusion although all six patients were injected with adrenaline at the time of procedure. The other three had only minor sphincterotomy site bleeding, which was not associated with haematemesis, melaena, 
TABLE II Early complications ( $<30$ days)

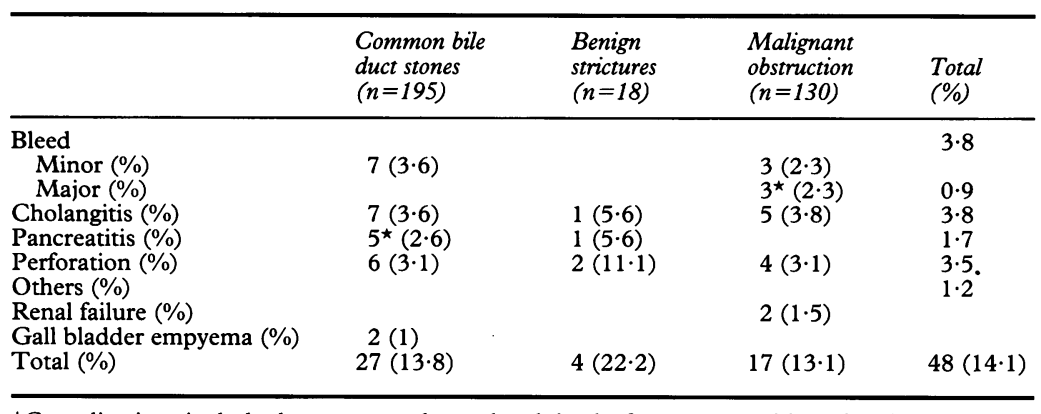

${ }^{\star}$ Complications include the two procedure related deaths from pancreatitis and major bleeding.

tachycardia or a fall in blood pressure or haemoglobin. Another five had post-procedural fever to $38^{\circ} \mathrm{C}$ in the first 36 hours. These five were diagnosed as cholangitis purely on the basis of exclusion of other causes. Four others had presumed retroperitoneal perforation either because of a contrast leak at ERCP (2), or because of a silent abdomen in the 24 hours after the procedure (2) although free air was not detected on chest or abdominal radiographs (Table II). All four patients were eating normally within 36 hours of the procedure.

Two others had worsening of the pre-existing renal failure. The 30 day mortality was 12 in 130 stented patients $(9.3 \%)$ with one procedure related death $(0 \cdot 8 \%)$. Twenty one of 130 malignant biliary obstruction patients were lost to follow up. Thus only 97 patients (130$(12+21))$ were followed up long term.

Of these 97, late complications occurred in $21(17 \cdot 8 \%)$, caused by stent blockage with or without cholangitis (20) and stent migration (1) (Table III). At the end of the review period, 25 patients were alive and the median survival in hilar, mid, and low common bile duct lesions were two, four, and 10 months respectively. Six patients with pancreatic carcinoma $(8.8 \%)$ and three patients with ampullary carcinoma $(20 \%)$, underwent curative surgical resection, with a median survival of 13 and 24 months respectively.

\section{Biliary obstruction resulting from common bile duct stones}

Of 201 patients with common bile duct stones, 35 had a previous cholecystectomy. Biliary stenting and drainage was established in $97 \%$ (195 of 201), although two patients with impacted ampullary stones, needed a combined percutaneous endoscopic approach. The causes of failure in six patients were, Billroth 2 gastrectomy (4), peripapillary diverticulum (1), and technical failure (1). Twenty nine patients had failed sphincterotomies at other hospitals. Either a sphincterotomy could not

TABLE III Late complications

\begin{tabular}{lcllc}
\hline & $\begin{array}{l}\text { Common bile } \\
\text { duct stones } \\
\left(n=183^{\star}\right)\end{array}$ & $\begin{array}{l}\text { Benign } \\
\text { strictures } \\
(n=14)\end{array}$ & $\begin{array}{l}\text { Malignant } \\
\text { obstruction } \\
(n=109 *)\end{array}$ & $\begin{array}{c}\text { Total } \\
(\%)\end{array}$ \\
\hline $\begin{array}{l}\text { Stent blockage/ } \\
\text { cholangitis (\%) }\end{array}$ & $\begin{array}{l}9(4 \cdot 9) \\
4(2 \cdot 2)\end{array}$ & $1(7 \cdot 1)$ & $20(18 \cdot 3)$ & $\begin{array}{r}9 \cdot 8 \\
1(0 \cdot 9)\end{array}$ \\
$\begin{array}{l}\text { Stent migration (\%) } \\
\text { Total (\%) }\end{array}$ & $13(7 \cdot 1)$ & $1(7 \cdot 1)$ & $21(19 \cdot 3)$ & $11 \cdot 4$ \\
\hline
\end{tabular}

${ }^{\star}$ Excluding patients who died in the first 30 days. be carried out or an inadequate sphincterotomy had been carried out. In each instance the 29 patients then had a sphincterotomy carried out in our department.

Early complications ( $<30$ days) (Table II), occurred in $13.8 \%$ (27 of 195). Seven patients had bleeding from the sphincterotomy site and none of them required blood transfusion. Another seven had post-procedural fever. Of the six patients with presumed retroperitoneal perforation four did not have any free air on radiography. All four were eating normally within 36 hours of the procedure. Six had pancreatitis. One of these died of acute fulminant pancreatitis (procedure related), while another developed empyema of the gall bladder and needed an urgent cholecystectomy. All other complications were treated medically.

The 30 day mortality was $2 \cdot 6 \%$ (five of 195 ), the deaths resulting from acute pancreatitis, pulmonary embolus, hepatic tuberculosis, and sepsis in two patients. In both patients who died from sepsis a second ERCP done three weeks after the original procedure confirmed patency of the biliary stent. A postmortem examination on one of them showed gall bladder empyema.

Bile duct clearance was obtained in 92 of $183(50 \cdot 3 \%)$ patients, most of whom required two endoscopic attempts and their stents were removed. The median interval between the initial procedure and duct clearance was two months (range, one to six). Fifty three of these patients subsequently had a cholecystectomy, seven patients were lost to follow up, and seven died of unrelated causes. Eighty patients with retained duct stones, had longterm biliary stents inserted for 12-48 months (median 30). In forty five elderly and frail patients, this was the definitive treatment. All of them had one or more underlying medical disorders and surgical treatment was not considered. In 35 patients further endoscopic attempts resulted in eventual bile duct clearance in 18 patients after a median interval of 15 months (range 4-31). This required three to four endoscopic attempts in 12 patients and two attempts in six. Four patients underwent cholecystectomy, two with bile duct exploration. The overall bile duct clearance rate was therefore $60 \cdot 1 \%$ (110 of 183) after excluding patients who had either died within the first 30 days or who were subsequently lost to follow up (12 of 195).

Late complications occurred in $7 \cdot 1 \%$ (13 of 183) of patients and were caused by cholangitis in $4.9 \%$ (nine of 183 ), and stent migration in $2.2 \%$ (four of 183 ). In patients with longterm biliary stents, cholangitis occurred in $7.5 \%$ (six of 80 ) and stent migration in $2.5 \%$ (two of 80 ). Complications were treated by antibiotics and stent change and no patient required surgery. Twenty three, 30 , and 20 patients with biliary stents were followed up for over 12, 24, and 36 months respectively (median follow up 30).

Biliary obstruction resulting from benign strictures In 18 patients, biliary obstruction resulted from benign strictures associated with chronic 
pancreatitis (8), postoperative strictures (5), periaortic fibrosis (2), choledochal cyst (1), and strictures of unknown aetiology (2).

Biliary stenting was successful in all patients, with early complications ( $<30$ days) occurring in $22.2 \%$ (four of 18 ) because of retroperitoneal perforation with no detectable free air on radiographs (2), post-procedural fever (1), and pancreatitis (1) (Table II). Two patients, one with the choledochal cyst and another with chronic fibrosing pancreatitis, had surgical drainage procedures, after they had recovered from their acute illness four months and eight months after the initial stent insertion. Three patients died of unrelated causes and four were lost to follow up. Late complications (Table III) occurred in one patient caused by cholangitis $(5 \cdot 6 \%)$. Nine patients had biliary stents inserted for 12-48 months (median 24), although one patient had the stent removed at 12 months, after showing patency of the previously strictured area.

\section{Discussion}

In patients with bile duct stones, surgical exploration of the duct is associated with a death rate of $2 \cdot 5-8 \%$, elderly patients being at greatest risk. ${ }^{19} 20$ Postoperative complications can occur in up to $46 \%$ of patients. ${ }^{20} \mathrm{By}$ contrast endoscopic sphincterotomy and stone extraction, has been reported with significant complications in only $10 \%$, with a $1.5 \%$ death rate $^{21}$ and has therefore been advocated as the preferred method of treatment in the elderly and the high surgical risk patient. ${ }^{622}$ In this study, the complication rate was higher at $14 \%$, which reflects both the severity of the acute illness in these elderly patients, as well as our strict adherence to the defined complications. Thus in the malignant group of patients three had minor bleeds and four had questionable true retroperitoneal perforation. In the benign group seven had minor bleeds and another four questionable perforations. These minor and questionable complications total 18 , and if they are excluded our total complication rate falls to 30 of $343(8 \cdot 8 \%)$.

Large bile duct stones, or those located in the intrahepatic ducts or above a stricture, are difficult to extract and endoscopic procedures fail in about $10 \%$ of patients. ${ }^{22}{ }^{23}$ Although various lithotripsy techniques have been tried, with increasing effectiveness, ${ }^{23}$ they are yet to be perfected. In this study, the overall duct clearance rate was $60 \cdot 1 \%$, which is lower than other reported series. This was unrelated to any lack of enthusiasm to remove duct stones, as our repeated attempts in most patients, will testify. An unusual patient selection pattern was partly responsible as this value represents a clearance rate in a population of patients who needed stenting. In 29 patients (14.9\%), endoscopic stone extraction attempts had failed at the referring hospital and 45 other patients $(23.1 \%)$, were medically unfit and further surgical or endoscopic duct clearance was not considered and in some instances, was even refused by the patients or their families.

In strictures resulting from benign biliary disease, endoscopic stenting is effective in up to $88 \%$ of patients, strictures of acute onset being more amenable to endoscopic treatment. ${ }^{24-26}$ By comparison, despite technical difficulties, endoscopic stenting was successful in all our 18 patients. The high incidence of early complications, reflects the technical difficulties encountered during the procedure. All complications, however, were successfully treated medically, with no deaths.

In malignant biliary obstruction, curative surgery is only possible in a few patients and bypass procedures are associated with a mortality of $18-33 \% .{ }^{27} 28$ Surgical bypass and endoscopic stenting have similar success rates $(90 \%)$, but endoscopic stenting was associated with fewer procedure related complications ${ }^{29}$ and a significantly shorter hospital stay, ${ }^{30}$ although late complications of stent blockage and cholangitis are more common. ${ }^{2}$ Endoscopic stenting has also been shown to be superior to percutaneous stenting, in malignant obstructive jaundice, with a significantly higher success rate and a significantly lower 30 day mortality. ${ }^{31}$

When our study first started, we tried nasobiliary drainage in a few patients with retained duct stones, as that was being currently recommended. ${ }^{32}$ We however preferred biliary stenting, as nasobiliary drainage was more time consuming, unpleasant, and a hindrance for the patient and did not seem to be any more effective than stenting. Endoscopic follow up in these patients, was only arranged once every 12 months, as stents are known to mechanically prevent stone migration and impaction and permit biliary drainage, despite being blocked. ${ }^{411}$

We did a small sphincterotomy in all our patients with malignant bile duct obstruction, as most returned for a second, third or even a fourth stent change and it was much simpler to change a stent in the presence of a small sphincterotomy. In addition some of our patients with a tortuous and tight malignant stricture required dilatation using two to three dilators as well as two to three Olbert balloons. This took up to half an hour and during that time the position of the guidewire in a few cases was lost altogether. A papillotomy avoids the risk of failing to recannulate the papilla and may shorten the procedure time in a tired and agitated patient. Of course, we accept that all this has to be weighed against the risk of a significant complication of sphincterotomy. Indeed five of 17 (29\%) early complications in those with malignant biliary obstruction were definitely caused by the sphincterotomy. This value is unacceptably high, and we have concluded that routine sphincterotomy in malignant biliary obstruction is therefore better avoided. We believe it is essential to carry out an adequate endoscopic sphincterotomy, in the presence of stones that have not been removed. We have recorded under our care two patients who had a stent insertion for bile duct stones, which were not removed and in whom a sphincterotomy was not carried out. Both of these patients returned within two months with recurrent cholangitis and we 
believe that the incidence of cholangitis will be increased in patients who do not have a sphincterotomy for common bile duct stones and in whom a stent has been inserted.

Fifty three patients in our study underwent cholecystectomy despite endoscopic clearance of bile duct stones. Cholecystectomy at least in the elderly is unnecessary, but all the important series published so far, show a 5-10\% recurrence rate of cholecystitis and cholangitis. ${ }^{33-35}$ In our 53 patients, a $10 \%$ chance of subsequent complications was unacceptable, particularly as the patients were fit after their endoscopic procedure and they chose to have surgery. The decision was made by the patients and their families.

There are only a few published reports on endoprosthesis insertion for retained bile duct stones. Siegel et al described 22 cases, median follow up 16 months and no complications were reported. ${ }^{8}$ Cotton et al followed up 17 patients for a median period of 39 months, and two patients $(11.8 \%)$ required surgery for biliary sepsis. ${ }^{7}$ Cairns et al reported on 90 patients, 41 being treated by endoprosthesis insertion alone and followed up for a mean of 15.9 months. Six patients $(14.6 \%)$ developed cholangitis and were treated by antibiotics or stent change. ${ }^{12}$ Dufek et al described 15 cases, median follow up 25 months, biliary complications occurring in five patients $(33.3 \%)$, two requiring surgery. ${ }^{13}$ Soomers et al followed up 26 patients for a median period of 26 months. Complications occurred in six patients (23\%), from stent blockage/migration and duodenal perforation and five of them underwent surgery. ${ }^{10}$ Peters et al described 40 cases, 27 of whom were treated only by endoprosthesis insertion and were followed up for a median of 13 months. Complications occurred in eight patients $(20 \%)$, two requiring surgery and there were two deaths. ${ }^{11}$ In our study, the late complication rate of $7 \cdot 1 \%$ resulted from cholangitis $(4 \cdot 9 \%)$ and stent migration $(2 \cdot 2 \%)$.

These figures, in our opinion, favourably support the use of biliary stenting in patients with retained duct stones.

In conclusion, endoscopic biliary stenting services are necessary in a district general hospital, providing palliation in malignant obstructive jaundice and offering an alternative therapeutic approach, in selected cases with retained bile duct stones. We are aware that our follow up period is not particularly long and that further controlled studies are required, on the issue of longterm stenting in benign biliary disease.

1 Huibregste K, Tytgat GN. Palliative treatment of obstructive jaundice by transpapillary introduction of large bore tive jaundice by transpapillary introduction of
bile duct endoprosthesis. Gut 1982; 23: 371-5.

2 Leung JWC, Emery R, Cotton PB, et al. Management of malignant obstructive jaundice at The Middlesex Hospital. Br f Surg 1983; 70: 584-6.

3 Siegel JH, Snady H. The significance of endoscopically placed prosthesis in the management of biliary obstruc- non-operative decompression in 277 patients. $\mathrm{Am} \mathcal{F}$ Gastroenterol 1986; 81: 634-41.

4 Burcharth F, Ingemann Jensen L, Olesen K. Endoprosthesis for internal drainage of the biliary tract. Gastroenterology 1979; 77: 133-7.

5 Cotton PB. Duodenoscopic placement of biliary prosthesis to relieve malignant obstructive jaundice. Br f Surg 1982; 69: $501-3$

6 Summerfield JA. Biliary obstruction is best managed by endoscopists. Gut 1988; 29: 741-5.

7 Cotton PB, Forbes A, Leung JWC, et al. Endoscopic stenting for long-term treatment of large bile duct stones: 2- to 5-year follow-up. Gastrointest Endosc 1987; 33: 411-2.

8 Siegel JH, Yatto RP. Biliary endoprosthesis for the management of retained common duct stones. Am $\mathcal{F}$ Gastroenterol 1984; 79: 50-4.

9 Kiil J, Kruse A, Rokkjaer M. Large bile duct stones treated by endoscopic biliary drainage. Surgery 1989; 105: 51-6.

10 Soomers AJ, Nagengast FM, Yap SH. Endoscopic placement of biliary endoprostheses in patients with endoscopically unextractable common bile duct stones. Endoscopy 1990; 22: 24-6.

11 Peters R, Macmathuna P, Lombard M, Karani J, Westaby $D$. Management of common bile duct stones with a biliary endoprosthesis. Gut 1992; 33: 1412-5.

12 Cairns S, Dias L, Salmon P, Cotton PB. Management of failed endoscopic clearance of the common bile duct. Gastroenterology 1988; 94: A57.

13 Dufek V, Benes J, Chmel J, Kordac V. Biliary endoprosthesis in the treatment of large common bile duct stones: 2 to 5 year follow up. Endoscopy 1990; 22: 240.

14 Demling L, Sueberth K, Rieman JF. A mechanical lithotriptor. Endoscopy 1982; 14: 100 .

15 Cotton PB, ERCP. Gut 1977; 20: 316-41.

16 Classen M, Demling L. Endoskopische Sphinkterotomie der papilla vateri und Steinextraktion aus dem ductus choledochus. Dtsch Med Wochenschr 1974; 99: 496-7.

17 Rao KJM, Blake H, Theodossi A. Use of a modified angioplasty balloon catheter in the dilatation of tight biliary strictures. Gut 1990; 31: 565-7.

18 Shorvon PJ, Cotton PB, Mason RR, Siegel JH, Hatfield ARW. Percutaneous transhepatic assistance for duodenoscopic sphincterotomy. Gut 1985; 26: 1373-6.

19 Vellacott KD, Powell PH. Exploration of the common bile duct: a comparative study. Br $\mathcal{F}$ Surg 1979; 66: 389-91.

20 Crumplin MKH, Jenkinson LR, Kassab JY, et al. Management of gallstones in a district general hospital. $\mathrm{Br}$ Management of gallstones

21 Cotton PB, Lehman G, Vennes MD, et al. Endoscopic sphincterotomy complications and their management: an attempt at consensus. Gastrointest Endosc 1991; 37: 383-93.

22 Cotton PB. Endoscopic management of bile duct stones; (apples and oranges). Gut 1984; 25: 587.

23 Classen M, Hagenmuller F, Knyrim K, Frimberger E. Giant bile duct stones - non surgical treatment. Endoscopy 1988; 20: 21-6.

24 Geenen DJ, Geenen JE, Hogan WJ, et al. Endoscopic therapy for benign bile duct strictures. Gastrointest Endosc 1989; 35: 367-71.

25 Berkelhammer C, Kortan P, Haber GB. Endoscopic biliary prostheses as treatment for benign postoperative bile duct
strictures. Gastrointest Endosc 1989; 35: 95-101.

26 Huibregste K, Katon RM, Tytgat GNJ. Endoscopic treatment of post operative biliary strictures. Endoscopy 1986; 18: $133-7$

27 Blumgart LH, Hadjis NS, Benjamin IS, Beazley R. Surgical approaches to cholangiocarcinoma at confluence of hepatic ducts. Lancet 1984; i: 66-9.

28 Sarr MG, Cameron JL. Surgical palliation of unresectable carcinoma of the pancreas. World $\mathcal{A}$ Surg 1984; 8: 906-18.

29 Dowsett JF, Russell RCG, Hatfield ARW, Cotton PB, Speer AG, Houghton J, et al. Malignant obstructive jaundice: What is the best management? - A prospective randomised trial of surgery $\mathrm{v}$ endoscopic stenting. [abstract]. Gut 1988; 29: A1493.

30 Shepherd HA, Royle G, Ross APR, et al. Endoscopic biliary endoprosthesis in the palliation of malignant obstruction of the distal common bile duct: a randomised trial. $\mathrm{Br} \mathcal{F}$ Surg 1988; 75: 1166-8.

31 Speer AG, Cotton PB, Russel RCG, et al. Randomised trial of endoscopic versus percutaneous stent insertion in malignant obstructive jaundice. Lancet 1987; ii: 57-62.

32 Cotton PB, Williams CB. Practical gastrointestinal endoscopy. 3rd ed. Oxford: Blackwell Scientific, 1990: 132-3.

33 Siegel JH, Safrany L, Ben-Zvi JS, et al. The significance of duodenoscopic sphincterotomy in patients with gallbladder in situ: report of s series of 1272 patients. $A m \mathcal{F}$ Gastroenterol 1988; 83: 1255-8.

34 Davidson BR, Neoptolemos JP, Carr-Locke DL Endoscopic sphincterotomy for common bile duct calculi Endoscopic sphincterotomy for common bile duct calculi
patients with gallbladder in situ considered unfit for patients with gallbladder in situ
surgery. Gut 1988; 29: 114-20.

35 Tanaka M, Ikeda S, Yoshimoto $H$, Matsumoto S. The long term fate of the gallbladder after endoscopic sphincterotomy. Complete follow up study of 122 patients. $A m$ f Surg 1987; 154: 505-9. 